\title{
Minimally Invasive Surgery in Pediatric Oncology: Proposal of Guidelines
}

\author{
PRZEMYSLAW GALAZKA ${ }^{1}$, KRZYSZTOF CZYZEWSKI $^{2}$, AGATA MARJANSKA ${ }^{2}$, \\ IRENA DANILUK-MATRAS ${ }^{1}$ and JAN STYCZYNSKI ${ }^{2}$ \\ ${ }^{1}$ Department of General and Oncological Surgery for Children and Adolescents, Jurasz University Hospital, \\ Collegium Medicum in Bydgoszcz, Nicolaus Copernicus University in Torun, Bydgoszcz, Poland; \\ ${ }^{2}$ Department of Pediatric Hematology and Oncology, Jurasz University Hospital, \\ Collegium Medicum in Bydgoszcz, Nicolaus Copernicus University in Torun, Bydgoszcz, Poland
}

\begin{abstract}
Background/Aim: The objective of the study was to propose clinical guidelines for the use of minimally invasive surgery (MIS) in pediatric oncology. Patients and Methods: Two groups of experts, including pediatric surgeons and pediatric oncologists were created in order to establish strategies of diagnostic and therapeutic surgical management in pediatric oncology. Results: On the basis of the analysis of the existing literature, we elaborated guidelines that were graded according to the simple practical clinical system: yes/no. This project was dedicated to the following topics: adrenal tumors including neuroblastoma, renal tumors including Wilms tumor (nephroblastoma), ovarian tumors and pulmonary nodules and metastases (osteosarcoma). Conclusion: Although existing data do not allow the recommendation of the use of MIS for all indications, this technique should currently be regarded as a standard of care in several areas of pediatric oncology.
\end{abstract}

Minimally invasive surgery (MIS), in contrast to open surgery, is a technique that limits the size of incisions that allow access to peritoneal or thoracic cavities, followed by the use of laparoscope or thoracoscope for visualization and precise dissection. The same target operation should be performed via an open technique or a minimally invasive approach (1-3).

This article is freely accessible online.

Correspondence to: Przemyslaw Galazka, MD, Ph.D., Department of General and Oncological Surgery for Children and Adolescents, Jurasz University Hospital, Collegium Medicum, Nicolaus Copernicus University in Torun, ul. Sklodowskiej-Curie 9, 85-094 Bydgoszcz, Poland. Tel: +48 525854015, Fax: +48 525854093, email: galazkaprzemek@hotmail.com

Key Words: Minimally invasive surgery, pediatric oncology, neuroblastoma, Wilms tumor, ovarian tumor, lung metastases, review.
The concept of MIS in children with cancer was used for the first time by Holocomb et al. (4), who showed laparoscopy and thoracoscopy to be highly accurate with minimal morbidity for the patient. Both modalities were useful for biopsies, assessment of resectability, staging, evaluation of metastatic or recurrent disease, assessing the potential benefit of second-look procedures, and for diagnosis of infectious complications. The development of this technology has been possible with improved visualization of anatomical structures (5). Subsequent studies and analyses confirmed that MIS procedures in pediatric oncology are safe and effective, resulting in earlier administration of adjuvant therapy.

MIS is a developing concept, however in contrast to many areas in adults (6-8), there are no clear guidelines or recommendations in pediatric oncology, mainly due to heterogeneity of clinical diagnoses and small numbers of patients included in the studies. Thus, the aim of this study was to propose clinical guidelines for the use of MIS in pediatric oncology.

\section{Guideline Development Overview}

Two initial groups of experts, including pediatric surgeons and pediatric oncologists were created in order to establish strategies of diagnostic and therapeutic surgical management in pediatric oncology. According to our own experience the relevant issues of MIS utilization in pediatric oncology were defined as follow: adrenal tumors including neuroblastoma (NBL), renal tumors including Wilms tumor (WT), ovarian tumors, pulmonary nodules and metastases. The main desired outcome was evidence of a reduction in open surgery, and secondary outcomes included efficacy and safety, expressed as rate of complications. We performed Pub Med searches from 1995 to 2019 to identify potentially relevant English-language studies. The searches included a combination of indexed terms 
and free text terms (minimally invasive surgery, laparoscopy, thoracoscopy, AND pediatric, child AND adrenal tumor, retroperitoneal tumor, neuroblastoma, Wilms tumor, ovary, thoracic/lung nodules/metastases). We screened references for other potentially relevant papers. On the basis of these analyses, we elaborated clinical guidelines that were graded according to the simple practical system: yes/no.

\section{Advantages and Disadvantages of MIS}

Minimally invasive surgical approach is increasingly used in a variety of pediatric tumor types. So far, there has been no pediatric oncology trial comparing MIS and open approaches. The real challenge in pediatric surgical oncology is that any specific tumor is rare and each subtype usually presents a distinct biologic entity (1). Heterogeneity of tumor types makes a uniform approach difficult and the number of each specific tumor type for most surgeons is small. No single pediatric oncology center is able to diagnose and treat a sufficient number of patients to prepare evidence-based recommendations on surgical approach and operative techniques, while multicenter trials are difficult to organize and control $(1,2)$.

Advantages of MIS. This approach, based on better visualization and shorter operative time, results in smaller incisions and lower operative trauma, shorter post-operative course and pain, better cosmesis, earlier post-operative feeding, quicker return to regular activities and earlier initiation of adjuvant chemotherapy. An additional benefit of MIS is less tissue trauma leading to fewer post-operative complications, less bowel adhesion formation, fewer wound complications and immunologic advantages. MIS may cause less pain, scarring, damage to healthy tissue and the patient may have a faster recovery than with traditional surgery $(9,10)$.

Disadvantages of MIS. Since complete tumor resection is one of the most important factors of survival in pediatric malignancies, the risk of incomplete resection or tumor spillage is a key issue during MIS. In the case of a R1/R2 resection, the prognosis is worse and intensified chemotherapy or radiotherapy might be required in order to minimize the risk of tumor recurrence. Inadequate lymph node sampling will cause errors of staging and risk classification (11).

Unique challenges to MIS in pediatric surgical oncology. Pediatric patients have usually smaller bodies, that imposes a challenge because of restricted working space for large tumors, the need for a larger incision for extraction, difficulty in navigation or limited room for stapler, use of adequate instrumentation, anesthesia difficulties, specificities of thoracoscopy (lung collapse required) and laparoscopy (insufflation, push of diaphragm, hypercapnia), port site metastases, and risk of visceral injury with trocar placement. Additionally, lack of experience and learning curve might be an issue (12). Apart from possible difficulties in vascular control, the oncologic nature of the disease may cause the risk of dispersion of tumor with insufflation, tumor spillage or incomplete resection within tumor margins. There is also an obvious risk of conversion of MIS approach to open surgery because limited tactile sense or localization or the need of a larger incision to remove the tumor intact.

\section{Pediatric Oncology: Summary of Reported Data}

Indications. MIS can be used in pediatric oncology either for diagnosis (biopsy) or treatment (tumor resection). MIS biopsy can be regarded as the management of choice in suspicion of neuroblastoma (NBL), hepatoblastoma (HBL), soft tissue sarcoma (STS) and germ cell tumor (GCT), while the indications for MIS biopsy are questionable in suspicion of Wilms tumor (WT), adrenocortical tumors, and pancreatic tumors. MIS tumor resection can be considered for localized NBL (L1 stage), adrenal tumors, renal tumors and pancreatic tumors, while it might be questionable for ovarian tumors, liver tumors, nephronsparing surgery (NSS) in Wilms tumors, and soft tissue sarcoma $(1,2,11,13-16)$.

Principles. General considerations for MIS in pediatric oncology require that the basic operative principles of open pediatric cancer surgery should be known and followed: avoiding spill, R0 resection, specimen intact, organ-sparing and optimal lymph nodes sampling. Purpose-specific considerations include proper biopsy, proper staging and proper resection (17). Systematic reviews of larger pediatric studies have been recently presented by Abdelhafeez et al. (3) and Phelps et al. (2).

Outcome. The summary of 8 studies performed between 2007-2018 aimed at evaluating MIS in tumor resection, including 213 patients, showed gross total resection in $94.3 \%$, with negative margins in $77.0 \%$ and a $10.8 \%$ (23/213) conversion rate to open surgery, leading to a median overall survival of $100 \%$ (range $=84-100 \%$ ) and median event-free survival $95 \%$ (range $=77-100 \%$ ) at median followup of 28 months (range=16-58 months) $(14,15,18-24)$. The conversion rate itself, reported in 14 large studies including $>50$ patients each, was $15.5 \%$ (214/1379) $(3,4,14,24-34)$.

\section{General Considerations on MIS}

Because the role of surgical radicality in pediatric oncology can vary from biopsy only to definitive total resection with negative microscopical margins, MIS should be regarded as a potential 
approach to achieve a dynamic series of therapeutic objectives. The surgical panels should be prepared for active surgical approaches stratified by tumor size, location, stage, resectability, histology, and available adjuvant therapies. MIS approaches to pediatric tumors should be undertaken with caution simultaneously with traditional open resection approach. During MIS operation, specimens should be placed in a dedicated retrieval bag and removed totally through an enlarged incision, disabling tumor dissemination. The fundamental principles have been outlined by several teams $(1,5)$.

Recommendations:

- During MIS approach, the operative field should be optimally exposed for surgeon.

- Tumor dissection should proceed from the peripheral to central area and saving division of critical structures until the tumor has been isolated.

- Every attempt should be undertaken by the surgeon to remove the tumor mass without spillage.

- The rescue plan for an intraoperative bleeding should be prepared by the operating surgeon.

\section{Adrenal Tumors}

In case of adrenal tumors, the common histologies include neuroblastic tumors, adrenocortical carcinoma (ACC), and benign adrenal tumors. The goals of surgery for neuroblastic tumors are variable, but $\mathrm{R} 0$ resection is not always required. For ACC, complete resection without spillage or positive margins and lymphadenectomy, when nodes are involved is mandatory. Classical indications where MIS is commonly used involve neuroblastic tumors of L1 stage and small, benign adrenal tumors. Controversies include neuroblastic tumors of L2 stage and tumors suspected of being ACC.

Neuroblastoma. The International Neuroblastoma Risk Group staging system (INRGSS) (35) is based on four stages: L1 (localized, no IDRF; image-defined risk factors), L2 (loco-regional, 1 or more IDRF), M (distant metastases (except MS stage)) and MS (with metastases to skin, liver, and bone marrow in patients aged $<18$ months). Neuroblastic tumor without IDRF and with a tumor volume less than 100 $\mathrm{ml}$ is regarded as amenable to MIS resection (2).

MIS approaches in adrenal tumors. Based on a relatively large number of retrospective studies, preference for laparoscopic approach can be given in adrenal tumors in INRGSS stage L1 or INSS stage I/II. Safe resection can be expected for tumors with a diameter of less than $4 \mathrm{~cm}$, and complete tumor resection at the range of $88-100 \%$. Still, conversion rate is $10-15 \%$ and surgical complication rate is about $10-30 \%(2,5,10,36)$.
Recommendations:

- MIS is recommended for diagnostic biopsy in adrenal tumors.

- Therapeutic MIS resection is recommended for neuroblastic tumor without IDRF and with a tumor volume less than $100 \mathrm{ml}$.

- The risk of disease- or treatment-related complications is 10-30\%.

\section{Renal Tumors}

Histologies of pediatric renal tumors include mostly (in almost $90 \%$ ) Wilms tumor (nephroblastoma) and rarely clear cell sarcoma of kidney, malignant rhabdoid tumor of kidney, renal cell carcinoma (RCC) and mesoblastic nephroma. Goals of surgery are: complete resection with negative margins, no spillage and sampling of lymph nodes, particularly in Wilms tumor. Relatively common indications where MIS is used (at least for adults) is RCC, while there are controversies about Wilms tumor in case small tumors, especially if centrally located, nephron-sparing surgery and sampling of lymph nodes.

Wilms tumor. Total tumor resection after induction chemotherapy is required followed by adjuvant chemotherapy. Usually surgeons have to proceed with large and fragile tumor with a high risk of intra-operative spillage. In most cases open surgery is necessary. The experience with MIS includes a limited number of patients with smaller tumors, and high rate of insufficient lymph node sampling (5, 37-39).

SIOP/RTSG (International Society of Pediatric Oncology/ Renal Tumor Study Group) listed contraindications to MIS in case of: tumor infiltrations on extrarenal structures, tumor extension beyond the border of the spinal column, thrombus in the renal vein or cava vena, tumor without any response to chemotherapy, and lack of experience in laparoscopic urology (20).

According to the SIOP-2001 Nephroblastoma protocol (Societe Internationale D'Oncologie Pediatrique - International Society of Paediatric Oncology), Wilms tumor represents the majority of cases and should be treated with pre-operative chemotherapy without an initial biopsy. Thus, adopted preoperative biopsy is used only in selected cases and imaging-guided core needle biopsy is the preferred technique in these cases (40). With respect to surgical treatment, there is an absolute tendency toward the conventional open tumor nephrectomy as has been reported in a recent survey (40). An additional drawback of the MIS techniques is the issue of inadequate lymph node sampling $(20,41)$.

Recommendations:

- MIS is not the recommended approach even in selected cases when biopsy is required in renal tumor.

- There is clear expert consensus against laparoscopic tumor nephrectomy. 


\section{Ovarian Tumors}

Spectrum and goals of surgery in ovarian tumors include: malignant tumor (salpingoophorectomy, inspect other ovary, nodes, omentum, collect ascites) and benign tumor (ovarysparing tumor excision). Surgical approach largely depends on size, solid nature and serum markers. In all these cases, MIS is commonly used. Other group of indications deals with fertility preservation. Still, there might be some controversies about total intact removal of tumor.

Ovarian tumors. Laparoscopy has a clear role in staging of malignant lesions, inspection of the diaphragm and the other ovary, any sampling from peritoneum can be performed with this technique. The role of MIS in ovarian surgery is not univocal. It has been suggested that tumors with diameter $<7.5 \mathrm{~cm}$ bring little risk for tumor spillage, so may be approached laparoscopically and removed safely $(1,5)$. In other cases, there are insufficient data to support the use of laparoscopy in the treatment of ovarian malignancies and an open approach is rather recommended in pediatric oncology $(42,43)$. MIS approaches that preserve ovarian parenchyma are favored in the treatment of benign adnexal masses and ovarian cysts. However, when compared to an open cystectomy, MIS has been associated with a higher rate of benign cyst rupture (1).

Fertility preservation. MIS approaches can be used for fertility preservation. Surgery leading to ovarian transposition or ovarian cryopreservation are accomplished laparoscopically. This approach is of value in case of planned pelvic irradiation, since already radiation doses of 4-20 Gy may have contributed to loss of ovarian function, thus ovarian transpositions out of the pelvis into paracolic areas can be recommended (44).

Recommendations:

- MIS is recommended in staging of malignant ovarian tumors.

- Tumors with diameter $<7.5 \mathrm{~cm}$ may be approached and removed laparoscopically.

- MIS technique is of clinical value in fertility preservation procedures.

\section{Lung Nodules and Metastases}

Biology of lung nodules is benign in majority (>90\%) of pediatric cases (infection, congenital, atelectasis, neoplastic); while cancer lesions from non-pulmonary metastasis and primary lung malignancies in children include $<10 \%$ and $<1 \%$ of lung nodules, respectively. Goals of surgery vary and are histology-dependent: e.g. diagnostic in Wilms tumor; therapeutic in osteosarcoma. Indications where MIS is commonly used are diagnosis and therapy, depending on histology, localization and number of nodules. Severe controversies exist with respect to osteosarcoma (OS) metastases.

MIS in thoracic tumors. Thoracoscopic approach is used for biopsy and resection of neurogenic tumors. Gross total resection is combined with a good outcome; conversion rate is at the level of $5-10 \%$ and surgical complication rate comparable to open approach $(1,5)$. In case of malignant immature teratomas, $\mathrm{R} 0$ resection without tumor spillage is the most important prognostic factor; it is essential to minimize the risk of disruption of the tumor and its local dissemination including negative margins. MIS approach in these cases should be used only if these principles are secured (5).

Lung metastases. Risk factors influencing decision on selection of surgical technique include: detection of metastases in CT (computed tomography) scan, number of metastases (with variable cut-offs ranging between 5-15), military disease ( $>25$ ), impalpable metastases, judgement of metastases viability, involvement of vessels or main bronchial branches, or response to previous chemotherapy $(45,46)$.

Metastatic osteosarcoma. Even though thoracoscopic tumor biopsy is now considered to be the preferred method for obtaining tissue for diagnostic purposes, the MIS approach to metastatic OS is not indicated in pediatric oncology (1). Since the ability to achieve a complete resection of recurrent disease is the most important prognostic factor for relapse, this usually cannot be achieved with MIS. Also, CT is not sufficiently informative about the extent of disease found intraoperatively and more lesions are detected at the time of thoracotomy than identified on preoperative CT (45), so thoracotomy is usually advocated (1). Patients with OS with metachronous metastatic pulmonary disease presenting with a single pulmonary nodule (SPN) on CT frequently require multiple thoracotomies, and two-thirds of patients have a second pulmonary relapse with a significant portion being ipsilateral.

Video-assisted thoracoscopic surgery (VATS) is recommended for SPN with subpleural location and other than OS histology, while the use of thoracoscopy for resection of OS lung nodules is not advocated (47). Manual identification of deeper lesions is difficult for the surgeon during VATS. The majority of SPN can be identified during thoracoscopy by using localizing techniques, including CTguided radioisotope marking using a gamma probe during VATS or hookwire localization based on injection of methylene blue, or intrathoracoscopic ultrasound $(48,49)$.

Recommendations:

- MIS is the preferred method for obtaining lung tissue for diagnosis. 
- Thoracoscopic approach is recommended for resections in thoracic neurogenic tumors.

- Due to low probability of complete resection of all lesions, MIS approach to lung metastatic osteosarcoma is not recommended.

\section{Future Perspectives}

New developments (robotic; virtual methods; 3D MIS; SILS, single-incision laparoscopic surgery; NOTES, natural orifice transluminal endoscopic surgery) will definitively widen the possibilities of pediatric oncological surgery in the future $(50,51)$. So far robot-assisted solid tumor resections have been used in abdominal, pelvic, thoracic, and neck localization with comparable, to other MIS techniques, rate of conversion to open surgery and tumor spillage (50).

\section{Conclusion}

Although existing data do not allow the recommendation of the use of MIS for all indications, this technique should currently be regarded as a standard of care in several areas of pediatric oncology. It is commonly used in suprarenal L1 neuroblastoma, small ovarian teratoma, and thoracic neural tumors. It has limited indications in Wilms tumor and osteosarcoma lung metastases. Existing contraindications include coagulopathy, respiratory insufficiency, and histology of ACC. Still, the success of this approach depends on the technical equipment and the experience of the surgeon.

\section{Conflicts of Interest}

The Authors have no conflicts of interest to disclose in regard to this study.

\section{Authors' Contributions}

PG, JS - concept/design, data analysis/interpretation, writing article, critical revision of article, approval of article; AM, KC, IDM - data collection, data analysis/interpretation, writing article, critical revision of article, approval of article.

\section{References}

1 Christison-Lagay ER and Thomas D: Minimally invasive approaches to pediatric solid tumors. Surg Oncol Clin N Am 28(1): 129-146, 2019. PMID: 30414678. DOI: 10.1016/ j.soc.2018.07.005

2 Phelps HM and Lovvorn HN, 3rd: Minimally invasive surgery in pediatric surgical oncology. Children (Basel) 5(12), 2018. PMID: 30486309 . DOI: 10.3390/children5120158

3 Abdelhafeez A, Ortega-Laureano L, Murphy AJ, Davidoff AM, Fernandez-Pineda I and Sandoval JA: Minimally invasive surgery in pediatric surgical oncology: Practice evolution at a contemporary single-center institution and a guideline proposal for a randomized controlled study. J Laparoendosc Adv Surg Tech A 29(8): 10461051, 2019. PMID: 31241404. DOI: 10.1089/lap.2018.0467

4 Holcomb GW, 3rd, Tomita SS, Haase GM, Dillon PW, Newman $\mathrm{KD}$, Applebaum $\mathrm{H}$ and Wiener ES: Minimally invasive surgery in children with cancer. Cancer 76(1): 121-128, 1995. PMID: 8630863. DOI: 10.1002/1097-0142(19950701)76:1<121::aidcncr2820760119>3.0.co;2-\#

5 Fuchs J: The role of minimally invasive surgery in pediatric solid tumors. Pediatr Surg Int 31(3): 213-228, 2015. PMID: 25588746. DOI: $10.1007 / \mathrm{s} 00383-015-3660-9$

6 Marano L, Rondelli F, Bartoli A, Testini M, Castagnoli G and Ceccarelli G: Oncologic effectiveness and safety of splenectomy in total gastrectomy for proximal gastric carcinoma: Metaanalysis of randomized controlled trials. Anticancer Res 38(6): 3609-3617, 2018. PMID: 29848717. DOI: 10.21873/anticanres. 12635

7 Machairas N, Papaconstantinou D, Stamopoulos P, Prodromidou A, Garoufalia Z, Spartalis E, Kostakis ID and Sotiropoulos GC: The emerging role of laparoscopic liver resection in the treatment of recurrent hepatocellular carcinoma: A systematic review. Anticancer Res 38(5): 3181-3186, 2018. PMID: 297151 60. DOI: 10.21873 /anticanres.12582

8 Campi R, Tellini R, Sessa F, Mari A, Cocci A, Greco F, Crestani A, Gomez Rivas J, Fiori C, Lapini A, Gallucci M, Capitanio U, Roupret M, Abaza R, Carini M, Serni S, Ficarra V, Porpiglia F, Esperto F, Minervini A and European Society of Residents: Techniques and outcomes of minimally-invasive surgery for nonmetastatic renal cell carcinoma with inferior vena cava thrombosis: A systematic review of the literature. Minerva Urol Nefrol 71(4): 339-358, 2019. PMID: 30957477. DOI: 10.23736/S0393-2249.19.03396-4

9 Iwanaka T, Kawashima H and Uchida H: The laparoscopic approach of neuroblastoma. Semin Pediatr Surg 16(4): 259-265, 2007. PMID: 17933668. DOI: 10.1053/j.sempedsurg.2007.06.008

10 Malkan AD, Loh AH and Sandoval JA: Minimally invasive surgery in the management of abdominal tumors in children. $\mathbf{J}$ Pediatr Surg 49(7): 1171-1176, 2014. PMID: 24952811. DOI: 10.1016/j.jpedsurg.2014.04.010

11 Fuchs J, Schafbuch L, Ebinger M, Schafer JF, Seitz G and Warmann SW: Minimally invasive surgery for pediatric tumors - current state of the art. Front Pediatr 2: 48, 2014. PMID: 24918096. DOI: 10.3389/fped.2014.00048

12 Adikibi BT, Mackinlay GA, Clark MC, Duthie GH and Munro FD: The risks of minimal access surgery in children: An aid to consent. J Pediatr Surg 47(3): 601-605, 2012. PMID: 22424362. DOI: $10.1016 /$ j.jpedsurg.2011.12.009

13 Warmann S, Fuchs J, Jesch NK, Schrappe M and Ure BM: A prospective study of minimally invasive techniques in pediatric surgical oncology: Preliminary report. Med Pediatr Oncol 40(3): 155-157, 2003. PMID: 12518343. DOI: 10.1002/mpo.10234

14 Metzelder ML, Kuebler JF, Shimotakahara A, Glueer S, Grigull L and Ure BM: Role of diagnostic and ablative minimally invasive surgery for pediatric malignancies. Cancer 109(11): 2343-2348, 2007. PMID: 17450589. DOI: 10.1002/cncr.22696

15 Leclair MD, de Lagausie P, Becmeur F, Varlet F, Thomas C, Valla JS, Petit T, Philippe-Chomette P, Mure PY, Sarnacki S, Michon $\mathrm{J}$ and Heloury Y: Laparoscopic resection of abdominal neuroblastoma. Ann Surg Oncol 15(1): 117-124, 2008. PMID: 17926102. DOI: 10.1245/s10434-007-9499-0 
16 Hubertus J, Boxberger N, Redlich A, von Schweinitz D and Vorwerk P: Surgical aspects in the treatment of adrenocortical carcinomas in children: Data of the GPOH-met 97 trial. Klin Padiatr 224(3): 143-147, 2012. PMID: 22504769. DOI: 10.1055/s0032-1304627

17 Cecchetto G, Riccipetitoni G, Inserra A, Esposito C, Michelazzi A, Ruggeri G, Spinelli C, Lima M and Italian Group of Pediatric Surgical O: Minimally-invasive surgery in paediatric oncology: Proposal of recommendations. Pediatr Med Chir 32(5): 197-201, 2010. PMID: 21171519.

18 Fraga JC, Rothenberg S, Kiely E and Pierro A: Video-assisted thoracic surgery resection for pediatric mediastinal neurogenic tumors. J Pediatr Surg 47(7): 1349-1353, 2012. PMID: 22813795. DOI: $10.1016 /$ j.jpedsurg.2012.01.067

19 Kelleher CM, Smithson L, Nguyen LL, Casadiego G, Nasr A, Irwin MS and Gerstle JT: Clinical outcomes in children with adrenal neuroblastoma undergoing open versus laparoscopic adrenalectomy. J Pediatr Surg 48(8): 1727-1732, 2013. PMID: 23932613. DOI: $10.1016 /$ j.jpedsurg.2013.03.056

20 Warmann SW, Godzinski J, van Tinteren H, Heij H, Powis M, Sandstedt B, Graf N, Fuchs J and Surgical Panel of the SRTSG: Minimally invasive nephrectomy for wilms tumors in children data from SIOP 2001. J Pediatr Surg 49(11): 1544-1548, 2014. PMID: 25475791. DOI: 10.1016/j.jpedsurg.2014.06.005

21 Irtan S, Brisse HJ, Minard-Colin V, Schleiermacher G, Canale S and Sarnacki S: Minimally invasive surgery of neuroblastic tumors in children: Indications depend on anatomical location and image-defined risk factors. Pediatr Blood Cancer 62(2): 257261, 2015. PMID: 25284263. DOI: 10.1002/pbc.25248

22 Malek MM, Mollen KP, Kane TD, Shah SR and Irwin C: Thoracic neuroblastoma: A retrospective review of our institutional experience with comparison of the thoracoscopic and open approaches to resection. J Pediatr Surg 45(8): 1622-1626, 2010. PMID: 20713210. DOI: 10.1016/j.jpedsurg.2010.03.018

23 Phelps HM, Ayers GD, Ndolo JM, Dietrich HL, Watson KD, Hilmes MA and Lovvorn HN, 3rd: Maintaining oncologic integrity with minimally invasive resection of pediatric embryonal tumors. Surgery 164(2): 333-343, 2018. PMID: 29751968. DOI: 10.1016/j.surg.2018.03.020

24 Spurbeck WW, Davidoff AM, Lobe TE, Rao BN, Schropp KP and Shochat SJ: Minimally invasive surgery in pediatric cancer patients. Ann Surg Oncol 11(3): 340-343, 2004. PMID: 14993031. DOI: 10.1245 /aso.2004.04.021

25 Ezekian B, Englum BR, Gulack BC, Rialon KL, Kim J, Talbot LJ, Adibe OO, Routh JC, Tracy ET and Rice HE: Comparing oncologic outcomes after minimally invasive and open surgery for pediatric neuroblastoma and wilms tumor. Pediatr Blood Cancer 65(1), 2018. PMID: 28792662. DOI: 10.1002/pbc. 26755

26 Acker SN, Bruny JL, Garrington TP and Partrick DA: Minimally invasive surgical techniques are safe in the diagnosis and treatment of pediatric malignancies. Surg Endosc 29(5): 12031208, 2015. PMID: 25159642. DOI: 10.1007/s00464-014-3795-0

27 Gomez-Chacon Villalba J, Rodriguez Caraballo L, Marco Macian A, Segarra Llido V and Vila Carbo JJ: Minimally invasive surgery in pediatric oncology. Tertiary center experience. Cir Pediatr 28(3): 105-110, 2015. PMID: 27775302

28 Esposito C, Lima M, Mattioli G, Mastroianni L, Riccipetitoni G, Monguzzi G, Zanon G, Cecchetto G, Settimi A, Jasonni V and Italian Society of Videosurgery in I: Thoracoscopic surgery in the management of pediatric malignancies: A multicentric survey of the Italian Society of Videosurgery in Infancy. Surg Endosc 21(10): 1772-1775, 2007. PMID: 17356939. DOI: 10.1007/s00464-0079246-4

29 Guye E, Lardy H, Piolat C, Bawab F, Becmeur F, Dyon JF, Marteau M, Lavrand F, Lefebvre F, Podevin G, Reinberg O and Varlet F: Thoracoscopy and solid tumors in children: A multicenter study. J Laparoendosc Adv Surg Tech A 17(6): 825829, 2007. PMID: 18158820. DOI: 10.1089/lap.2007.0043

30 Lacreuse I, Valla JS, de Lagausie P, Varlet F, Heloury Y, Temporal $\mathrm{G}$, Bastier $\mathrm{R}$ and Becmeur $\mathrm{F}$ : Thoracoscopic resection of neurogenic tumors in children. J Pediatr Surg 42(10): 1725-1728, 2007. PMID: 17923203. DOI: 10.1016/j.jpedsurg.2007.05.030

31 Smith TJ, Rothenberg SS, Brooks M, Bealer J, Chang J, Cook BA and Cullen JW: Thoracoscopic surgery in childhood cancer. J Pediatr Hematol Oncol 24(6): 429-435, 2002. PMID: 12218588. DOI: $10.1097 / 00043426-200208000-00004$

32 Rescorla FJ, West KW, Gingalewski CA, Engum SA, Scherer LR, 3rd and Grosfeld JL: Efficacy of primary and secondary video-assisted thoracic surgery in children. J Pediatr Surg 35(1): 134-138, 2000. PMID: 10646791. DOI: 10.1016/s0022-3468(00) 80030-5

33 Waldhausen JH, Tapper D and Sawin RS: Minimally invasive surgery and clinical decision-making for pediatric malignancy. Surg Endosc 14(3): 250-253, 2000. PMID: 10741443. DOI: $10.1007 / \mathrm{s} 004640000033$

34 Rao BN: Present day concepts of thoracoscopy as a modality in pediatric cancer management. Int Surg 82(2): 123-126, 1997. PMID: 9331836.

35 Monclair T, Brodeur GM, Ambros PF, Brisse HJ, Cecchetto G, Holmes K, Kaneko M, London WB, Matthay KK, Nuchtern JG, von Schweinitz D, Simon T, Cohn SL, Pearson $\mathrm{AD}$ and Force IT: The international neuroblastoma risk group (INRG) staging system: An inrg task force report. J Clin Oncol 27(2): 298-303, 2009. PMID: 19047290. DOI: 10.1200/JCO.2008.16.6876

36 Fascetti-Leon F, Scotton G, Pio L, Beltra R, Caione P, Esposito C, Mattioli G, Saxena AK, Sarnacki S and Gamba P: Minimally invasive resection of adrenal masses in infants and children: Results of a european multi-center survey. Surg Endosc 31(11): 4505-4512, 2017. PMID: 28550366. DOI: 10.1007/s00464-0175506-0

37 Chui $\mathrm{CH}$ and Lee AC: Peritoneal metastases after laparoscopic nephron-sparing surgery for localized wilms tumor. J Pediatr Surg 46(3): e19-21, 2011. PMID: 21376182. DOI: 10.1016/ j.jpedsurg.2010.11.024

38 Godzinski J, Graf N and Audry G: Current concepts in surgery for wilms tumor - the risk and function-adapted strategy. Eur $\mathrm{J}$ Pediatr Surg 24(6): 457-460, 2014. PMID: 25478666. DOI: $10.1055 / \mathrm{s}-0034-1396425$

39 Bouty A, Burnand K, Nightingale M, Roberts A, Campbell M, O'Brien $\mathrm{M}$ and Heloury Y: What is the risk of local recurrence after laparoscopic transperitoneal radical nephrectomy in children with wilms tumours? Analysis of a local series and review of the literature. J Pediatr Urol 14(4): 327 e321-327 e327, 2018. PMID: 29705138. DOI: 10.1016/j.jpurol.2018.03.016

40 Elgendy A, Shehata S, Medhat Zaki A and Shehata S: National survey on the management of wilms tumor. J Pediatr Hematol Oncol 41(4): 280-285, 2019. PMID: 30102647. DOI: 10.1097/ MPH.0000000000001289 
41 Harris AC, Brownlee EM, Ramaesh R, Jackson M, Munro FD and MacKinlay GA: Feasibility of laparoscopic tumour nephrectomy in children. J Pediatr Surg 53(2): 302-305, 2018. PMID: 29229481. DOI: 10.1016/j.jpedsurg.2017.11.032

42 Childress KJ, Santos XM, Perez-Milicua G, Hakim J, AdeyemiFowode O, Bercaw-Pratt JL and Dietrich JE: Intraoperative rupture of ovarian dermoid cysts in the pediatric and adolescent population: Should this change your surgical management? J Pediatr Adolesc Gynecol 30(6): 636-640, 2017. PMID: 28336475. DOI: 10.1016/j.jpag.2017.03.139

43 Liang H, Guo H, Zhang C, Zhu F, Wu Y, Zhang K, Li H and Han J: Feasibility and outcome of primary laparoscopic cytoreductive surgery for advanced epithelial ovarian cancer: A comparison to laparotomic surgery in retrospective cohorts. Oncotarget 8(68): 113239-113247, 2017. PMID: 29348902. DOI: $10.18632 /$ oncotarget.22573

44 Peycelon M, Audry G and Irtan S: Minimally invasive surgery in childhood cancer: A challenging future. Eur J Pediatr Surg 24(6): 443-449, 2014. PMID: 25478667. DOI: 10.1055/s-0034-1396419

45 Heaton TE and Davidoff AM: Surgical treatment of pulmonary metastases in pediatric solid tumors. Semin Pediatr Surg 25(5): 311-317, 2016. PMID: 27955735. DOI: 10.1053/j.sempedsurg. 2016.09.001

46 Croteau NJ and Heaton TE: Pulmonary metastasectomy in pediatric solid tumors. Children (Basel) 6(1), 2019. PMID: 30626161. DOI: 10.3390/children6010006

47 Parida L, Fernandez-Pineda I, Uffman J, Davidoff AM, Gold R and Rao BN: Thoracoscopic resection of computed tomographylocalized lung nodules in children. J Pediatr Surg 48(4): 750-756, 2013. PMID: 23583129. DOI: 10.1016/j.jpedsurg.2012.09.051
48 Fernandez-Pineda I, Daw NC, McCarville B, Emanus LJ, Rao BN, Davidoff AM and Shochat SJ: Patients with osteosarcoma with a single pulmonary nodule on computed tomography: A single-institution experience. J Pediatr Surg 47(6): 1250-1254, 2012. PMID: 22703801. DOI: 10.1016/j.jpedsurg.2012.03.033

49 Gonfiotti A, Davini F, Vaggelli L, De Francisci A, Caldarella A, Gigli PM and Janni A: Thoracoscopic localization techniques for patients with solitary pulmonary nodule: Hookwire versus radioguided surgery. Eur J Cardiothorac Surg 32(6): 843-847, 2007. PMID: 17913505. DOI: 10.1016/j.ejcts.2007.09.002

50 Cundy TP, Marcus HJ, Clark J, Hughes-Hallett A, Mayer EK, Najmaldin AS, Yang GZ and Darzi A: Robot-assisted minimally invasive surgery for pediatric solid tumors: A systematic review of feasibility and current status. Eur J Pediatr Surg 24(2): 127135, 2014. PMID: 23686663. DOI: $10.1055 / \mathrm{s}-0033-1347297$

51 Troccaz J, Dagnino G and Yang GZ: Frontiers of medical robotics: From concept to systems to clinical translation. Annu Rev Biomed Eng 21(4): 193-218, 2019. PMID: 30822100. DOI: 10.1146/annurev-bioeng-060418-052502
Received September 26, 2019

Revised October 17, 2019

Accepted October 24, 2019 